IMECE2007-43781

\title{
UNDERGRADUATE RESEARCH: EXPERIENCES FROM A THREE-YEAR PROJECT
}

\author{
Peter Schuster, Charles Birdsong, \\ California Polytechnic State University
}

\begin{abstract}
There are significant benefits of research for the involved undergraduate student. These include exposure to advanced topics, introduction to research methods, and direct interaction with faculty and other students. Faculty and institutions benefit as well by the increased interaction with students - fresh eyes in research projects, more energized research groups, and more engaged alumni. However, there are some challenges in designing a research program to work primarily with undergraduates. These include the students' lack of exposure to advanced topics, short tenure on the project, and potentially lower commitment to the results. There are a number of ways to address these concerns, however. Short student tenure and limited background can be offset by breaking up a long-term project into manageable short-term goals, allocating specific deliverables to each student, and implementing a rigorous data reporting and storage system. Motivation concerns can be handled through tying performance to student grades or to an external competition.

This paper presents results of applying these techniques in a multi-disciplinary vehicle sensing research project involving sixteen undergraduates over a three-year period. Although individual student time on the project ranged from only three to twelve months, all students were able to contribute to the project. Student activities were grouped into individual and small group tasks, each with specific goals and timetables. Rigorous electronic documentation and data storage techniques were employed to enable new students to come up-to-speed quickly. A mix of course credits, supplemental pay, and an intercollegiate competition were used to maintain student motivation. Project successes include high student satisfaction, conference papers, a demonstration pre-crash sensing system, and participation in an international student competition.
\end{abstract}

\section{INTRODUCTION}

Cal Poly is a polytechnic primarily undergraduate institution (PUI). The mechanical engineering department has $\sim 1000$ undergraduates and $\sim 30$ master's students, supported by 25 full-time faculty. As a result, faculty research activities involve a significant proportion of undergraduates. Since 2004, the authors have conducted a joint research program in collision avoidance and pre-crash sensing, centered in the mechanical engineering department. Our research activities have centered on the study of advanced automotive sensing technologies and control algorithms. While the research itself is interesting and significant due to the promise to deliver significant life-saving benefits to personal mobility, we are also interested in pursuing this work because of the benefits to the students. Student learning is the primary focus of higher education, and the experiences gained through research offer a significant learning possibilities for certain undergraduates. Recognizing that not all students are prepared for this (see Student Selection, below), those that are ready will gain a lot from the experience. Fifteen undergraduates and one graduate student have been involved in the present study, representing three different engineering departments.

This paper begins with a review of the major benefits of undergraduate research (for the prepared student) and proven techniques for managing undergraduate research projects. Then follows an introduction to our specific on-going research project and our project management system. Next, the link between project successes (and failures) and project management techniques is explored. The paper concludes with a discussion identifying which approaches were most important for project success. 


\section{BENEFITS OF UNDERGRADUATE RESEARCH}

Undergraduate research presents opportunities to significantly enhance the education of participating students. It also offers a number of benefits to the supporting faculty, department, and college. The major benefits are summarized in this section.

\section{For the Student}

A number of studies have used student and alumni surveys to quantify the benefits of undergraduate research to the student researchers (Bauer \& Bennett, 2003; Lopatto, 2004; Nagda et al., 1998). Their findings are summarized in this section.

Undergraduate research activities enhance student learning. Students who work on research projects learn by doing. They gain hands-on experience with research approaches and the scientific method. Research experiences provide the opportunity to apply classroom theories and assignments to the practice of engineering. Their increased knowledge enables them to converse at an advanced level about the discipline.

Student researchers gain a broad set of skills beyond their discipline. By observing how faculty are continuously learning, undergraduates begin to appreciate lifelong learning, whether or not they pursue post-graduate degrees. Former undergraduate researchers report improved critical thinking skills, higher self-confidence, and the ability to deal with openended problems. Research activities engage the students. They have the opportunity to be part of cutting-edge applications and advance the state of the art. This involvement sparks their intellectual curiosity and leads to greater involvement in the rest of their academic experience. Literature searching develops students as critical readers and thinkers. Paper preparation and presentation improve writing and speaking skills.

In addition to the research itself, the students benefit from a close interaction with other members of the research team. The connection established with a particular faculty member, and the close ties with both older and younger students on the project, creates an ideal mentoring environment. By working within a professional group, students learn to enhance their own professionalism and to work well in a team.

Involvement in undergraduate research activities has a positive impact on students' career opportunities. Student researchers have a higher retention rate and are more likely to continue into graduate school than their peers. Participation in a research project gives a graduate school applicant a valuable experience and advantage when their application is compared to others with similar high grade point averages and test scores. The experience of working on an open ended project and presenting and publishing the results allows undergraduates to decide if graduate school is a good choice for them. It should be noted that undergraduate students apply for graduate school at the beginning of their senior year so that research experience must be done before this if it is to enhance the student's graduate school application chances. A student research job improves students' marketability for employment in the field or graduate work-significantly more than other campus jobs.

\section{For the Faculty}

While not as widely studied as the benefits to students, working with undergraduate student researchers offers a number of rewards for the faculty member as well (Merkel, 2001). By working closer with certain students, and conveying higher-level skills than in the classroom environment, a professor remains more intellectually engaged in teaching. The student researchers enable the teacher to remain connected to the current student generation, thereby improving their classroom teaching skills.

A common motivation for research at PUI is that faculty can bring the research into the classroom and help to motivate otherwise dry, theoretical topics. Example problems or homework assignments can be based on problems taken from the research. While this can be done it, requires a significant time commitment especially considering that the state of the art of the research is constantly changing. Eventually the "new" lecture material becomes stale and outdated unless it is updated. Under the limited time constraints to prepare high quality lectures and perform research it is difficult to achieve this at a high level of success.

Undergraduates can also bring 'fresh eyes' to a research project. Because they are less fettered by past experiences or the currently accepted theories and have less at risk if the research is unsuccessful, they are freer to push the envelope.

At a PUI, undergraduate research may be the only opportunity for a faculty to perform research. As a result, this research has all the benefits we know flow from continued professional development of faculty members.

\section{For the College}

Departments and colleges that support undergraduate research activities gain a number of benefits as well (Merkel, 2001). Undergraduate researchers are more likely to have a strong positive undergraduate experience, which may translate into becoming active alumni. External recognition of a program is another benefit of undergraduate research. The enhancement of a college's reputation carries with it improvements in the areas of student recruitment, faculty recruitment, and corporate donations. For state institutions in particular, an improved reputation may translate into additional government funding for undergraduate programs.

At a PUI, working with undergraduates may be the only way to get research projects done. As a result, undergraduate research directly contributes to the continued professional development of faculty, leading to actively engaged scholars. These research activities may also lead to improved department and college facilities, through the sharing of research-funded equipment. 


\section{PROJECT MANAGEMENT TECHNIQUES}

Maintaining a cutting-edge research program with a score of undergraduates requires a significant amount of planning and organization. The major techniques associated with successful undergraduate research projects are summarized here. For more discussion of these, including sources, see Schuster \& Birdsong, 2006.

\section{Project Planning}

Research Topic Selection - Selecting a research topic appropriate for a group of undergraduates to handle is a significant challenge. It needs to have enough depth to contribute to the field (and engage the students), while not requiring substantial knowledge beyond the student's abilities taught in basic science, math, and engineering courses. In addition, the ideal topic will lend itself to dissection into small pieces, so that individual researchers or small teams can successively advance the work piecemeal. Successful research groups are formed around such topics, and can grow over time as the research progresses.

Reliable Funding Source - The need for a reliable source of funding cannot be overstated. Student researchers can receive independent study credit for work completed, but a longer-term commitment deserves pay. This is especially true for engineering undergraduates, where the intensive curriculum leaves little room for optional coursework. In addition, the research itself will require materials and equipment to fund, and these needs will change over time. The amount of funds required necessarily depends on the type of research and number of students, but some funding will certainly be necessary. To maintain a research direction with a series of undergraduates over time, the funding source should be longterm or renewable.

\section{Organization \& Training}

Student Selection - Research is not for everyone. The open-ended nature of research projects, with unanticipated obstacles and unpredictable outcomes, is unappealing to many undergraduates. In addition, to successfully manage a group of students simultaneously, each team member must be capable of self-direction and self-motivation. They need to possess the presence of mind to determine how to proceed when an obstacle is reached, and when to seek help versus proceeding on their own. These skills are rare in any individual, but result in the best research team members.

Team Continuity - Team member continuity and adequate training are closely related. Each student needs to have the proper skills for the job before they are tasked with an openended research problem. To ensure this, at first the faculty member must work closely with the students to discover what knowledge is lacking, and fill the gaps. However, due to the continuous turnover of students on the team (graduations, coops, internships, etc), a faculty member could easily spend most of his available time training new students. Instead, successful research groups need to take advantage of peer mentoring/training. In other words, experienced members of the research team are paired with new members to walk them through the challenges and make sure they don't get lost.

Project Documentation - An on-going knowledge base is also critical to team member training. In successful undergraduate teams, each student is responsible for documenting the results of their work, usually in the form of a report or technical paper, along with a presentation. Ideally, this work can be presented externally and adds to the group's engagement in the broader community of scholars. In addition to providing a focus for the individual student and a publication opportunity for all team members, this requirement ensures that knowledge gained is not subsequently lost as team members move on. By requiring an external publication, the student results will be captured in a concise, clear format for later team members to reference. This requirement is also good training for the student.

\section{Team Interactions}

Team Member Roles - Student researchers may work together on a team, but each should have their own specific tasks and goals clearly defined. With all of the competing pressures of the student life, ambiguity of direction will result in most undergraduates foundering. There should also be realistic short-term (weekly and monthly) goals along with their overall deliverables. This enables progress checks and gives a sense of contribution and satisfaction to team members.

On-Going Coaching - Continual close faculty interaction with the students is required to keep the students motivated and the research on-track. While clear initial direction and deliverables may be given at the outset, open-ended research will stumble on unanticipated challenges and opportunities that students may not be able to handle on their own. In addition, students may be initially uncomfortable with admitting their issues, so these need to be drawn out. Initially, meetings on a weekly basis are recommended.

Motivation - As with any human activity, motivation is a key component to research projects. Faculty members engage in research primarily for intrinsic reasons: the satisfaction of contributing to the broader knowledge base, of advancing one's own skills, or of solving problems. However, extrinsic rewards supplement these: summer salary, release time, publications, and recognition by one's peers. Students should have a similar mix of motivators. Careful selection of a research topic and student researchers will find an overlap of intrinsic rewards (i.e. the student should care about the research). However, a number of extrinsic rewards can be added as supplements: immediate benefits (course credit, pay), long-term benefits (resume builder, recommendation letter, publication), and soft rewards (encouragement, recognition of peers, travel opportunities).

\section{PROJECT BACKGROUND}

The research project described in this paper is aimed at creating and testing a low-cost vehicle collision detection 


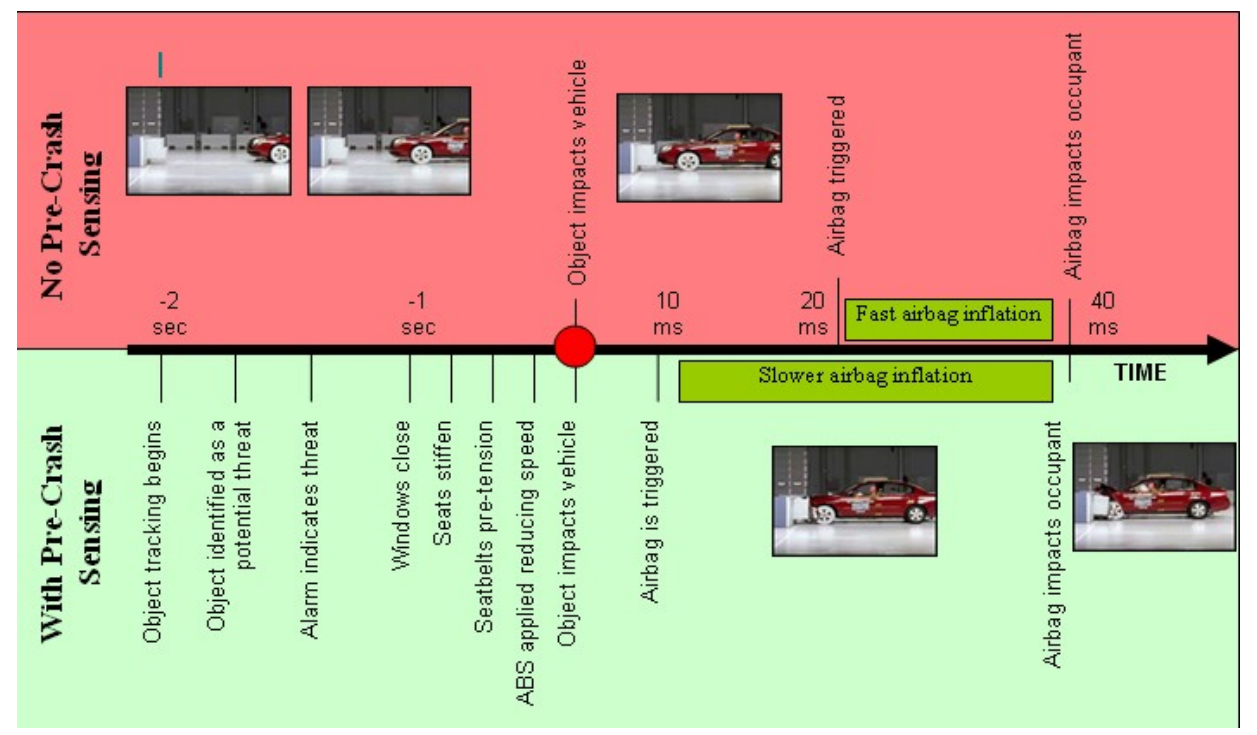

Figure 1. Timelines for collisions with and without pre-collision sensing.

system. The project is motivated by current accident rates and available vehicle passive safety technologies.

In the United States, motor vehicle crashes are the leading cause of death for persons of every age from 2 through 33. Since the 1960s, introduction of passive safety equipment (e.g. seat belts, air bags, crush structures) has dramatically reduced accident rates, injury severity and the number of fatalities; however the absolute number of deaths and injuries remains high. 6 million motor vehicle crashes each year result in over 40,000 deaths (NHTSA, 2007). Certain conditions (weather, lighting, impairment, distraction) limit drivers' effectiveness at recognizing and responding to dangerous situations. For example, $50 \%$ of fatal accidents occur outside of daylight hours and $12 \%$ during inclement weather. Driver distraction is cited as a contributing cause in half of all accidents. In order to significantly reduce accident severity and occurrence, future safety technologies must move beyond 'passive.' To support this, vehicles will require new exterior pre-collision sensors to create an electronic awareness of the traffic situation (Hover, et al, 2006).

Figure 1 illustrates some near-term safety benefits of precrash sensing. Current vehicles (top half of the figure) do not have any means of anticipating a crash. In the short timeframe (approximately 10-20 ms) after a crash is detected by acceleration-based sensors, the options for deploying safety technologies is limited. Currently, airbags are deployed approximately 10-20 ms after impact and must be inflated rapidly so that they are in place to protect the passenger. If the crash could be anticipated, additional time would be available to deploy new safety technologies such as audible alarms, seatbelt pre-tensioners, automatic door locks, seat stiffeners, seat position control, window closing, slower airbag inflation rates, and pre-crash braking (Lyons \& Taskin, 2000; BeutnagelBuchner, et al, 2004). Some of these features have recently been introduced in the Acura RL ("collision mitigation avoidance system"), Infiniti QX56, Lexus LS, IS, ES and GS ('Pre-Crash' - 2007 model includes rear monitoring), MercedesBenz S-Class ('Pre-Safe with brake support') and Volvo S80 ("collision warning and brake support"). The results are increased vehicle crash survival rates. In addition, pre-crash detection will reduce the incidence of unnecessary airbag deployment. Studies show that unnecessary airbag deployment can cause greater injuries than a minor crash would cause (Jones, 2002).

Beyond the passive safety technologies shown in Figure 1, an advanced pre-crash sensing system will also be capable of directing accident-avoidance technologies. For example, an automated braking system can augment a driver's braking force if the sensor determines more deceleration is necessary to stop the vehicle before impact. With increased sensor robustness, this system could be used to automatically apply the brakes when an imminent crash is predicted; regardless of whether braking is already applied.

\section{APPLYING PROJECT MANAGEMENT TECHNIQUES}

Most of the project management techniques described earlier have been used in the pre-collision sensing project. The specific approaches used are discussed in this section.

Research Topic Selection - The topic is relevant to both industry and government, offers a range of tasks with varying levels of complexity, and is of interest to undergraduates. It has the added benefit of being a multi-disciplinary study, which is of increasing importance in engineering education.

Reliable Funding Source - This research program has been funded by the California Central Coast Research Partnership and Lockheed Martin. Although these sources have provided some start-up funds, a search for long term funding to ensure project continuity is ongoing. Securing 
funding currently requires the majority of the investigators' time-leaving less time to contribute to the technical aspects of the project.

Student Selection - With sixteen students on the project Students have been selected by a combination of direct contact (from within classes) and job postings. We have been less successful hiring students based on job postings and reading resumes. Instead identifying good students in class has lead to the most successful members. The least successful students worked closely with others on tasks that were not as well defined. This allowed them to rely too much on others without producing their own results. In hind sight this situation could be helped by not allowing the scope to change or the deadlines to stretch out as the student continues to work on the project without producing results.

This project has included several interdisciplinary student teams with excellent outcomes. Students do not have many opportunities to work closely in an undergraduate program with students from other disciplines. This project as naturally needed the expertise of mechanical, electrical and computer science and engineering students who have worked together filling in each other's weaknesses and bringing understanding outside of the common experiences of intra-disciplinary students.

Team Continuity - This research has been successfully organized along the lines outlined in the paper. Students work together as needed to complete the tasks, and those with more experience on the project have acted as informal mentors and guides to the newer students. However, even with these guidelines, not all students have been successful. For example in one case a student quit the project without completing the assigned work even though he received a failing grade for course credit. However in all other cases students have completed their commitment and earned either course credit or a stipend.

Project Documentation - This research project uses Blackboard as the repository of knowledge. Students are continually reminded, "If it's not on Blackboard, then it doesn't exist." Although this reminder is sometimes necessary, the resulting documentation has been successful and newer team members have been able to mostly train themselves by reading about what already has been done. Data collected in Blackboard has also made preparation of publications easier. Other electronic tools such as literature search result databases help organize a rapidly growing reference list. Examples include Citeseer ( http://citeseer.ist.psu.edu) which allows you to automatically notified when a paper adds a reference to another paper that you are interested in. Also CiteULike is a free service to help academics to share, store, and organize the academic papers they are reading. When you see a paper on the web that interests you, you can click one button and have it added to your personal library. http://www.citeulike.org/. This allows teams to share reference lists.

Team Member Roles - Each student in the project is given a specific task and timeline for completion.
On-Going Coaching - Weekly meetings have proven to be necessary to create the link between the students and faculty.

Motivation - Students receive a mix of pay and course credit for their work.

\section{PROJECT RESULTS (TO DATE)}

Over the three years discussed here, undergraduates studied potential sensors (Carlin, et al, 2005), created formal test methods and evaluated these sensors (Birdsong, et al, 2006), developed physical and virtual simulators to test algorithms (Desrosiers, et al, 2007), and integrated sensors into a working prototype system.

\section{DISCUSSION}

The authors have successfully been engaged in research at a PUI while continuing to teach heavy teaching loads. The effort has had benefits to the students, faculty and the university.

Despite the benefits, performing research at a PUI has some limitations. The pace of development can be considerably slower than at an R1 university due to the limited time available to faculty, the short duration of involvement from undergraduate and master's students and the limited resources at a university where the focus is education. Publication is more difficult because undergraduate students are not as motivated as graduate students to publish their work. Competition for grants is difficult because the PUI does not have the same resources as the R1 university. For example it is difficult to conduct research while maintaining a high teaching load of 12 to 16 units a quarter. However many granting institutions will not support funds to release faculty from part of their teaching load to dedicate time to research. These institutions compare proposals from the PUI with those from an $\mathrm{R} 1$ where release time is built into the system, and perceive that the additional cost does not add value. On the other hand some grant opportunities have an educational component that the PUI is better at meeting than the R1.Since a traditional PUI does not have the resources to perform research, additional support is required from the university. The university can not simply mandate that faculty must do research without providing the tools to do it. This support may include release time to write proposals or to conduct research, matching funds for travel, materials, or administrative support, space to perform research, etc. Another important form of support is the acknowledgement from fellow faculty and university administration that research at the PUI is a valuable effort and worth the costs of time, space and other scarce resources and agreement that it helps to meet the mission of the PUI.

\section{CONCLUSIONS}

This paper outlines the benefits and techniques that have proven successful in undergraduate research at a PUI. It outlines the area of research in collision avoidance where the work has been conducted and discusses the project management techniques and results. While there are challenges 
and costs associated with this effort, if the work is carefully scoped, with proper management techniques and support from the university at all levels, research can provide benefits to all and help to meet the mission at the PUI.

\section{ACKNOWLEDGMENTS}

We would like to thank our students for making this work possible: Ronald Bermudes, Matt Brown, John Carlin, Justin Carpenter, Chris Corral, Dana Desrosiers, Handoko Hadisurya, Duane Howard, Daniel Kawano, Jason Kempenaar, Tyson Messori, Robert Muschiana, Danny Murphy, D.J. Parsons, William Thompson, and Taylor White. This research project has been supported by grants from Lockheed Martin, the Office of Naval Research through the California Central Coast Research Partnership.

\section{REFERENCES}

K.W. Bauer \& J.S. Bennett, "Alumni Perceptions Used to Assess Undergraduate Research Experience," The Journal of Higher Education 74.2: 210-230 (2003).

U. Beutnagel-Buchner, P.M. Knoll, B.J. Schaefer, H. Guettler, M. Bunse, R. Kallenbach, "Predictive Safety Systems - Steps Toward Collision Mitigation.” Paper 2004-01-1111, 2004 SAE World Congress.

C. Birdsong, P. Schuster, J. Carlin, D. Kawano, W. Thompson, J. Kempenaar, "Test Methods and Results for Sensors in a Pre-Crash Detection System.” Paper 2006-01-0142 in the Society of Automotive Engineers (SAE) World Congress, April 2006.

J. Carlin, C. Birdsong, P. Schuster, W. Thompson, D. Kawano, "Evaluation of Cost-Effective Sensor Combinations for a Vehicle Pre-crash Detection System.” Paper 2005-013578, SAE Commercial Vehicle Conference, November 2005.

D. Desrosiers, C. Birdsong, P. Schuster, "A Pre-Crash Simulator to Evaluate Vehicle Collision Prediction Algorithms.” Fifth IFAC Symposium on Advances in Automotive Control, August 2007.

N. Hover, B. Lichte, S. Lietaert, "Multi-beam LIDAR Sensor for Active Safety Applications.” Paper 2006-01-0347, 2006 SAE World Congress.

R.C. Jones, "Technologies for Static Airbag Suppression Systems.” 6th International Symposium on Sophisticated Car Occupant Safety Systems, Karlsruhe, Germany, December 2002.

D. Lopatto, "Survey of Undergraduate Research Experiences (SURE): First Findings.” Cell Biology Education 3: 270-277, Winter 2004.

C.T. Lyons and I. Taskin, "A Low-Cost MMIC-Based Radar Sensor for Frontal, Side or Rear Automotive Anticipatory Pre-Crash Sensing Applications.” IEEE Intelligent Vehicles Symposium, 2000.

C.A. Merkel, "Undergraduate Research at Six Research Universities: A Pilot Study for the Association of American Universities.” http://www.aau.edu/education/Merkel.pdf, 2001.

B.A. Nagda, S.R. Gregerman, J. Jonides, W. von Hippel, J.S. Lerner, "Undergraduate Student-Faculty Research Partnerships Affect Student Retention.” The Review of Higher Education 22.1: 55-72 (1998).

NHTSA, “Traffic Safety Facts 2005.” DOT HS 810 631, National Highway Traffic Safety Administration, www.nhtsa.dot.gov, 2007.

P. Schuster, C. Birdsong, "Research in the Undergraduate Environment.” 2006 ASEE Annual Conference, June 2006. 